\title{
Correction to: Early bone formation around immediately loaded implants with nanostructured calcium-incorporated and machined surface: a randomized, controlled histologic and histomorphometric study in the human posterior maxilla
}

\author{
Francesco Guido Mangano ${ }^{1,2}$. Giovanna lezzi ${ }^{3} \cdot$ Jamil Awad Shibli ${ }^{4}$ Jefferson Trabach Pires ${ }^{4} \cdot$ Giuseppe Luongo $^{5}$. \\ Adriano Piattelli ${ }^{6} \cdot$ Carlo Mangano $^{7}$
}

Published online: 18 September 2021

(c) Springer-Verlag GmbH Germany, part of Springer Nature 2021

\section{Correction to: Clinical Oral Investigations \\ https://doi.org/10.1007/s00784-017-2061-y}

Figure 5 was inadvertently published with this study but belongs to another study: Mangano C, Shibli JA, Pires JT, Luongo G, Piattelli A, Iezzi G. Early Bone Formation around Immediately Loaded Transitional Implants Inserted in the Human Posterior Maxilla: The Effects of Fixture Design and Surface. Biomed Research International 2017, Article ID 4,152,506. Figure 5 has been corrected hereby.

The original article can be found online at https://doi.org/10.1007/ s00784-017-2061-y.

Francesco Guido Mangano

francescoguidomangano@gmail.com

1 Department of Surgical and Morphological Science, Dental School, University of Varese, 21100 Varese, Italy

2 Piazza Trento 4, 22015 Gravedona, Como, Italy

3 Department of Medical, Oral, and Biotechnological Sciences, University of Chieti-Pescara, Chieti, Italy

4 Department of Periodontology, Oral Implantology Clinic, Dental Research Division, Guarulhos University, Sao Paulo, Brazil

5 Department of Oral and Maxillofacial Surgery, University of Naples, Naples, Italy

6 Department of Medical, Oral, and Biotechnological Sciences, University of Chieti-Pescara, Chieti, Italy

7 Department of Dental Sciences, University Vita Salute S. Raffaele, Milan, Italy

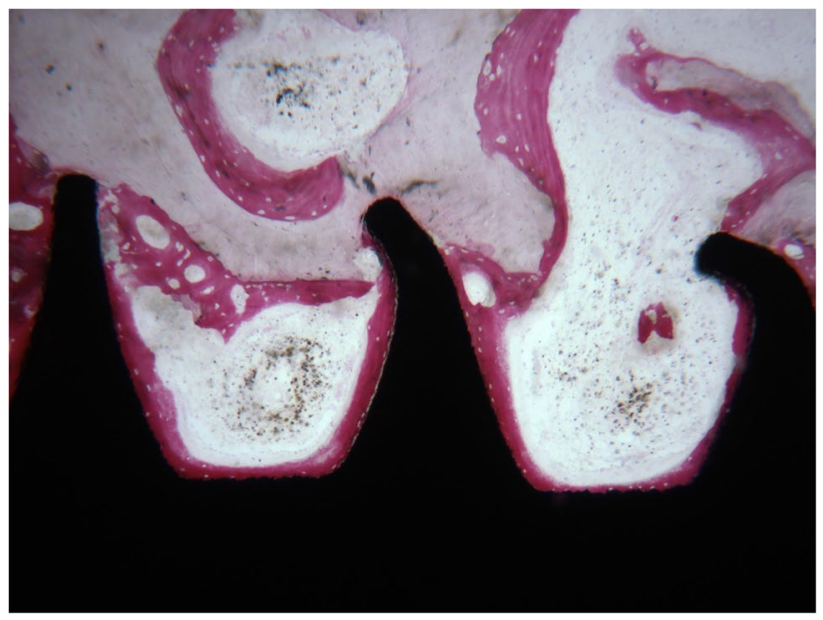

Fig. 5 Nanostructured calcium-incorporated (NCI) implant (test). The implant thread was lined by newly formed bone, and an intense osteoblastic activity was still evident. Acid fuchsin and toluidine blue, magnification $\times 40$

Publisher's note Springer Nature remains neutral with regard to jurisdictional claims in published maps and institutional affiliations. 